\title{
JORNADA DE ALFABETIZAÇÃO DE JOVENS E ADULTOS NO ESTADO DO MARANHÃO
}

\author{
Glaucia Sousa Moreno ${ }^{1}$ \\ Mileny Alves Bezerra²
}

\section{RESUMO}

Este artigo tem como objetivo analisar a experiência da Jornada de Alfabetização do Maranhão - Sim, eu posso! e Círculos de Cultura. Além disso, busca recuperar as ações do programa que visam a processos emancipatórios, para além do ensino da leitura e escrita para jovens e adultos. Para o desenvolvimento do trabalho, recorremos à pesquisa bibliográfica com referencial freireano, Freire (2000 e 2002), documental e à pesquisa participante, enquanto membro da brigada de alfabetização do Movimento dos Trabalhadores Rurais Sem-Terra (MST) responsável pela condução da Jornada de Alfabetização. Pretende-se, assim, que o trabalho possa contribuir com as reflexões sobre a educação de jovens e adultos e a educação popular, como importantes instrumentos de emancipação dos sujeitos.

Palavras-chave: Jornada de Alfabetização no Maranhão. Educação e Emancipação. Educação de Jovens e Adultos.

\footnotetext{
${ }^{1}$ Mestre em Agriculturas Familiares e Desenvolvimento Sustentável pelo Núcleo de Ciências Agrárias e Desenvolvimento Rural (NCADR) da Universidade Federal do Pará/Empresa Brasileira de Pesquisa Agropecuária - Amazônia Oriental/EMBRAPA. Doutoranda em Educação Científica e Tecnológica na Universidade Federal de Santa Catarina - UFSC. Professora no Curso de Licenciatura em Educação do Campo na Universidade Federal do Sul e Sudeste do Pará (UNIFESSPA). ORCID: http://orcid.org/0000-0003-1375-6985. Email: gs.moreno1@gmail.com

${ }^{2}$ Licenciada em Educação do Campo pela Universidade Federal do Sul e Sudeste do Pará. ORCID: http://orcid.org/0000-0002-4621-021X. E-mail: milenyalves.01@outlook.com
} 


\section{YOUTH AND ADULT LITERACY DAY IN THE STATE OF MARANHÃO}

\section{ABSTRACT}

This article aims to analyze the experience of Maranhão Literacy Day - Yes, I can! and Culture Circles. In addition, it seeks to recover the actions of the program aimed at emancipatory processes, in addition to teaching reading and writing to young people and adults. For the development of the work, we used bibliographic research with Freire's reference, Freire (2000 and 2002), documentary and participatory research, as a member of the literacy brigade of the Movimento dos Trabalhadores Rurais Sem-Terra (MST) responsible for conducting the Jornada de Literacy. It is intended, therefore, that the work can contribute to the reflections on the education of young people and adults and popular education, as important instruments for the emancipation of the subjects.

Keywords: Literacy Day in Maranhão. Education and Emancipation. Youth and Adult Education.

\section{DíA DE ALFABETIZACIÓN DE JÓVENES Y ADULTOS EN EL ESTADO DE MARANHÃO}

\section{RESUMEN}

Este artículo tiene como objetivo analizar la experiencia del Día de la Alfabetización de Maranhão - ¡Sí, puedo! y círculos culturales. Además, se busca recuperar las acciones del programa orientadas a los procesos emancipadores, además de la enseñanza de la lectura y la escritura a jóvenes y adultos. Para el desarrollo del trabajo se utilizó la investigación bibliográfica con referencia de Freire, Freire (2000 y 2002), investigación documental y participativa, como miembro de la brigada de alfabetización del Movimiento de Trabajadores Rurales Sin Tierra (MST) encargada de realizar la Jornada de Literatura. Se pretende, por tanto, que el trabajo pueda contribuir a las reflexiones 
sobre la educación de jóvenes y adultos y la educación popular, como importantes instrumentos para la emancipación de los sujetos.

Palabras clave: Día de la Alfabetización en Maranhão. Educación y Emancipación. Educación de jóvenes y adultos.

\section{INTRODUÇÃO}

Em 2017, fomos indicadas para compor a Brigada Nacional de Alfabetização Salete Moreno, que seria responsável pela condução da Jornada de Alfabetização do Maranhão - Sim eu posso! Círculos de Cultura. A Jornada, que é uma das ações do Plano Mais IDH, política do governo do estado do Maranhão, que atua nos 30 municípios de menor Índice de Desenvolvimento Humano Municipal (IDHM) do estado, ocorre por meio de uma parceria entre o MST e o Governo do Estado, e da Secretaria de Estado de Educação (SEDUC) e a Secretaria de Estado de Direitos Humanos e Participação Popular (SEDIHPOP). Já houve duas fases da Jornada (2016/2017 e 2017/2018). E quase 21 (vinte e um) mil jovens, adultos e idosos, em 15 municípios maranhenses, foram alfabetizados, utilizando o método cubano Sim, eu posso! Este combinado à experiência dos Círculos de Cultura freirianos, cujo objetivo consiste em contribuir para a superação dos alarmantes índices de analfabetismo do estado. 32440270

Lembramos de nossa felicidade com esse convite, porém não tínhamos a dimensão do que se tratava. Achávamos que esse seria, apenas, mais um programa de alfabetização, mais uma tarefa a cumprir, das mais importantes, certamente, pois a superação do analfabetismo é um passo importante para a construção de uma sociedade emancipada. Mas, logo nas primeiras formações da Brigada, relendo os livros que líamos no curso, como Pedagogia do Oprimido, de Paulo Freire, e outros escritos, sentíamos que a tarefa estaria além do ensino, leitura e escrita. Quando fomos para os municípios, percebemos que o que nós estudávamos no curso de Educação do Campo se materializava na Jornada. Pudemos perceber que ela ia de acordo com o curso, quando tratava da realidade dos sujeitos participantes, fazendo com que os sujeitos trouxessem suas 
experiências para dentro da Universidade, para o debate com o conhecimento científico, dando relevâncias aos seus conhecimentos empíricos, aperfeiçoados por meio do estudo. Essa práxis se materializava nos processos da Jornada de forma inexplicável, o que mobilizou nossa curiosidade em pesquisá-la.

Dentre tudo isso, nos chamou a atenção foi o quanto não compreendíamos a tarefa que assumiríamos. Pensávamos que coordenaríamos um processo de alfabetização de jovens e adultos, e que tal processo exigiria de nós um conhecimento técnico, mas não foi o que vivenciamos. Pudemos fazer parte de um grande processo de humanização e emancipação, da (re) construção de pessoas, de comunidades e de uma sociedade inteira. Por esse motivo, resolvemos encaminhar a pesquisa para este tema: compreensão dos elementos que fizessem com que a Jornada de Alfabetização fosse para além da mera alfabetização e caminhasse rumo à emancipação, tentando desvendar aquilo que tanto nos encantava na vivência deste processo.

A escolha deste tema foi reforçada pelo período histórico que estamos vivendo, um período de retrocessos, principalmente no âmbito da educação e de ataques diretos ao "patrono da educação brasileira". Paulo Freire nos deixou como legados, para além de seus grandes escritos, a inspiração para cumprirmos com a tarefa de realizar uma formação verdadeiramente humana dos sujeitos, que contribua com a libertação, e para a libertação da sociedade como um todo, tarefa que assumimos com afinco durante Jornada de Alfabetização do Maranhão.

Tendo escolhido nosso objeto de estudos, estabelecemos como objetivos: contextualizar sócio e educacionalmente o Maranhão em perspectiva histórica, analisar a atual realidade na qual a Jornada de Alfabetização está inserida; apresentar a Jornada de Alfabetização, e seus resultados, recuperar e analisar as experiências sensíveis dos educandos e educadores no município, destacando os limites e avanços da Jornada de Alfabetização no Maranhão.

Com isso, pretendemos que esta pesquisa possa colaborar com os estudos sobre o tema, trazendo novas perspectivas para a educação de jovens adultos e idosos, compreendendo-a como um importante instrumento de emancipação humana e mobilização 
popular. À guisa de conclusão, buscamos apontar alguns limites, estruturais e de gestão, e potencialidades, principalmente numa perspectiva de emancipação humana, que se apresentaram durante a Jornada, provocando a reflexão sobre alguns desafios a serem enfrentados para a projeção de novas fases desta surpreendente revolução que vem das letras.

\section{COMBATE AO ANALFABETISMO E A JORNADA DE ALFABETIZAÇÃO DO MARANHÃO}

Ao verificarmos o Índice de Desenvolvimento Humano Municipal da Educação (IDHM-E) maranhense, que foi calculado com base nos dados do Censo do IBGE de 2010, podemos notar que, "considerando as faixas de desenvolvimento do programa das nações unidas (PNUD), o estado do Maranhão se encontra com um dos menores índices de desenvolvimento totalizando $(0,49$ a 0,599$)$, na $19^{a}$ posição no Brasil, abaixo do indicador do plano nacional $(0,637) "$ (IMESC, 2015).

O cenário no campo maranhense é de uma população que teve seus direitos à educação e escolarização negados, de forma geral, constituindo uma população rural de $72,2 \%$ com menos de um ano de estudo ou sem instrução, segundo dados do instituto Maranhense de estudos socioeconômico e cartográficos, (IMESC, 2015). A taxa de analfabetismo entre as pessoas com mais de 15 anos que vive no campo é a segunda mais alta do país, com um percentual de 40,3\%; enquanto a taxa estadual é também bastante elevada, chegando a 20,8 \%. É ainda mais alarmante notar que, nos 30 municípios com Índices de Desenvolvimento Humano Municipal (IDHM) mais baixos, esse percentual chega a 65,9 \% da população (IBGE, 2010).

Desde a Segunda República, diversas foram as iniciativas desenvolvidas no Maranhão para superar os altos índices de analfabetismo, porém "as preocupações com o analfabetismo parecem estar mais no campo da retórica dos direitos sociais, do que na construção efetiva de políticas públicas para solucionar o 
problema" (MST/SEDUC, 2016, p.14), já que pouco incidiram na realidade do estado.

Historicamente, o direito à leitura e a escrita foi negado aos pobres, isso desde que as terras indígenas foram invadidas pelos portugueses. Apesar de a $1^{\mathrm{a}}$ primeira Constituição do Brasil independente, datada de 1824, ter anunciado o direito à educação, somente na Segunda República, ele foi de fato estendido a todos, com a Constituição de 1934, se tornando realidade para a maior parte da população brasileira já na década de 1990. Na atualidade, embora ainda não seja uma realidade efetiva para uma parcela da população, nossa Constituição Federal enuncia, no artigo 208, que: "o dever do Estado com a educação será efetivado mediante a garantia de: I educação básica obrigatória e gratuita dos 4 (quatro) aos 17 (dezessete) anos de idade, assegurada inclusive, sua oferta gratuita para todos os que a ele não tiveram acesso na idade própria;" (BRASIL, 1988).

No entanto, ao analisarmos os dados atuais do Maranhão, podemos perceber que o Estado não tem cumprido seu papel no tocante à educação da população e os altos índices de analfabetismo revelam que há dívida histórica com o povo maranhense, que chega a ser gritante. Essa dívida precisa, urgentemente, ser paga, não podemos aceitar que um estado tão rico em recursos e potencialidade produtiva, como o Maranhão, tenha sua história marcada pelo analfabetismo, que, nesse caso, se expressa como um projeto de dominação do seu povo.

Em terras tupiniquins, de capitalismo dependente, marcadas por um desenvolvimento desigual e combinado, pode-se prescindir de alfabetizar todo seu povo para manter certo nível de "desenvolvimento". A aposta parece ter sido investir na formação de uma elite dirigente e relegar ao povo uma formação quando muito rebaixada, deixando uma grande massa de jovens, adultos e idosos analfabetos, afeita ao trabalho bruto e a uma suposta cordialidade. (PERCASSI; GUEDES, 2019, p.21). 
No Maranhão, em meio a tantas privações já vividas na pele pelo povo, o direito de aprender a ler e escrever não é realidade para quase um quinto da população, que está relegada à condição de analfabeta. Essa realidade parece ser parte de um projeto de governo conduzido pela oligarquia maranhense, condição pensada como projeto governamental para a população mais pobre do estado, que teve de arcar com a conta de viver sem acesso aos direitos básicos. Grande parte da população, que tem seus territórios há décadas usurpados pela chamada oligarquia governamental, teve de suportar, ainda, o analfabetismo como carro chefe do Estado.

Não é preciso dizer que a exploração de corpos e mentes não seria a mesma se todos fossem alfabetizados, que a desigualdade não seria tamanha e a população teria voz, pois como nos ensina Paulo Freire (2002, p. 193): "não é possível atuar em favor da igualdade, do respeito aos direitos à voz, à participação, à reinvenção do mundo, num regime que negue a liberdade de trabalhar, de comer, de falar, de criticar, de ler, de discordar, de ir e vir, a liberdade de ser".

Ao analisarmos a fundo quem são as pessoas que tiveram e têm suas histórias marcadas pela falta de políticas públicas efetivas, podemos perceber que são na sua grande maioria os negros, indígenas, quilombolas, camponeses, ribeirinhos; homens e mulheres que tiveram sua história marcada pela negação do direito à leitura e à escrita e, quase sempre, entraram para as estatísticas como sujeitos em situação de extrema pobreza.

Para alguns, há pouco significado em não ser alfabetizado, mas, para muitos, esta é uma marca indelével, motivo de vergonha e humilhação, que anuncia um destino sem futuro. No entanto, embora seja propagandeado que estudar ou não seja uma questão de mérito ou esforço pessoal, em geral, àqueles e àquelas que não estudaram foi negada a oportunidade de aprender a ler e escrever. Tinham de escolher entre comer ou aprender a ler, entre andar quilômetros a pé na esperança de aprender a escrever e a sobrevivência e essas histórias se repetiam e se repetem por gerações nas famílias maranhense.

Para que essa sina não se repita, não basta que aqueles que não estão alfabetizados queiram mudar essa condição, é preciso que o governo se arme de vontade política e crie condições, por meio de 
políticas públicas, que possibilitem jovens, adultos e idosos a recobrarem sua condição de cidadania, aprendendo a ler e escrever. Mais ainda, é preciso que a sociedade esteja convencida da necessidade de garantir esse direito a toda a população, para que tenhamos um país mais justo, construído pelo conjunto dos sujeitos emancipados.

\section{A Jornada de Alfabetização do Maranhão}

O estado do Maranhão inicia o combate ao analfabetismo a partir da ruptura com as oligarquias políticas, representada pela família Sarney, com a eleição de um governo de caráter mais progressista, em 2006, com o então governador Jackson Lago. No entanto, este não conseguiu cumprir completamente o mandato, pois foi retirado do poder por estas mesmas oligarquias em março de 2009.

Apesar da retirada precoce do governador, este promoveu importantes avanços no combate ao analfabetismo, quando iniciou uma jornada de alfabetização em áreas de assentamentos e acampamentos, em parceria com o Movimento dos Trabalhadores Rurais Sem Terra (MST).

Em 2015, com a eleição do Governador Flávio Dino (PCdoB), a oligarquia maranhense sofre uma nova derrota, pois o governo assume nitidamente um caráter progressista, que tem como uma de suas ações o combate à pobreza.

Com isso, em 2016, inicia-se uma nova fase de combate ao analfabetismo, ampliando as propostas já iniciada pelo governador Jackson Lagos, quando esse tema passa se a constituir como uma das ações do Plano Mais IDH, que tem os seguintes objetivos:

O plano de ações 'Mais IDH' terá por objetivo promover a superação da extrema pobreza e das desigualdades sociais no meio urbano e rural, por meio de estratégia de desenvolvimento territorial sustentável, abrangendo: I - integração de políticas públicas com base no planejamento territorial; II ampliação dos mecanismos de participação popular na gestão das políticas públicas de interesse do 
desenvolvimento dos municípios; III - ampliação da oferta dos programas básicos de cidadania; IV inclusão e integração produtiva das populações pobres e dos segmentos sociais mais vulneráveis, tais como trabalhadores rurais, quilombolas, indígenas e populações tradicionais, calcado em um modelo de desenvolvimento que atenda às especificidades de cada um deles; $\mathrm{V}$ - valorização da diversidade social, cultural, econômica, política, institucional e ambiental das regiões e das populações (MARANHÃO, 2015).

O plano tem como principal tarefa construir políticas públicas que melhorem o desempenho escolar, a saúde pública e a renda, nos 30 municípios de menor percentual no ranking do IDHM do estado do Maranhão.

No âmbito da educação, entre as ações do Plano, está previsto o combate ao analfabetismo, por meio do chamado Mais Alfabetização, articulado com base em dois programas: o Brasil Alfabetizado, em parceria com o Governo Federal e a Jornada de Alfabetização do Maranhão. Para a coordenação da Jornada, o governador Flávio Dino convida o Movimento Sem-Terra, já que o Movimento tem larga experiência na alfabetização de jovens e adultos, articulando o método cubano Sim, eu posso! aos Círculos de Cultura da pedagogia Freireana ${ }^{3}$.

O Sim, eu posso! (Yo, si puedo!) é um método cubano de alfabetização, que foi desenvolvido por um grupo de profissionais da educação do Instituto Pedagógico Latino-americano e Caribenho IPLAC, em meados dos anos 1990. O método, inspirado na campanha de alfabetização realizada em Cuba, de 1961, já alfabetizou mais de 9 milhões de pessoas em mais de 30 países, tendo sido "traduzido e contextualizado para 10 (dez) idiomas e dialetos, como: espanhol, português, francês, chinês, créole, ayamará, quíchua, Guarany e

\footnotetext{
${ }^{3}$ Desde 2006, o MST vem desenvolvendo processos de alfabetização massiva, com base no método Sim, eu posso!, tanto em parceria com governos, como de forma independente, tendo atuado nos estados de: Alagoas, Bahia, Maranhão, Minas Gerais, Pernambuco, Pará, Paraná, Piauí, Rio Grande do Norte, Sergipe e Ceará. Neste último, coordenou um projeto massivo em parceria com a prefeitura de Fortaleza, chamado Fortaleza Alfabetizada, em que mais de 15 mil pessoas se alfabetizaram.
} 
tétum. Também existem versões em braile e para surdos" (MST/SEDUC, 2016, p.12).

Já os Círculos de Cultura são uma releitura da experiência desenvolvida por Paulo Freire, na década de 1960, que levava o mesmo nome. Mais que um método, os Círculos extrapolam "a execução de etapas preestabelecidas sendo mais uma epistemologia e um conjunto de indicações teórico-metodológicas" (MST/SEDUC, 2018, p.4), que foram combinadas à práxis educativa da Educação Popular desenvolvida pelo MST, ao longo de sua trajetória.

A Jornada de Alfabetização do Maranhão foi projetada para acontecer em 12 (doze) meses de trabalho, sendo 8 (oito) meses de alfabetização, destes, 4 (quatro) meses com o método Sim, eu posso!, em que os educandos aprendem os rudimentos da leitura e da escrita e 4 (quatro) meses com os Círculos de Cultura, em que é realizado um aperfeiçoamento desse processo e 4 (quatro) meses para preparação e finalização do projeto. A primeira fase da Jornada aconteceu entre os anos de 2016 e 2017, em oito dos trinta municípios com os mais baixos IDHM do estado: Água Doce do Maranhão, Aldeias Altas, Governador Newton Bello, Itaipava do Grajaú, Jenipapo dos Vieiras, Santana do Maranhão, São João do Caru e São Raimundo do Doca Bezerra. Segue abaixo um panorama geral da realidade do analfabetismo em cada um dos municípios.

Para conduzir esse processo, o MST formou uma brigada de educadores militantes, a Brigada Nacional de Alfabetização Salete Moreno, que recebeu esse nome em homenagem a uma grande militante da região, assentada e pedagoga da primeira turma de Pedagogia da Terra do estado do Pará, falecida em 2008. A Brigada foi composta, na sua primeira fase, por 20 brigadistas militantes do MST, oriundos de 10 (dez) estados do Brasil (AL, BA, CE, MA, PI, RJ, $\mathrm{RO}, \mathrm{RS}, \mathrm{SC}, \mathrm{SP}$ ). Essa militância foi responsável pela coordenação e acompanhamento político e pedagógico do processo a nível local e estadual. Seguem a seguir os resultados obtidos nesta primeira fase da Jornada. 
Tabela 01: Quantitativos de sujeitos alfabetizados pela $1^{\text {a }}$ fase da Jornada de Alfabetização do Maranhão

\begin{tabular}{|c|c|c|c|c|c|c|}
\hline $\begin{array}{l}\text { MUNICIP } \\
\text { IOS DE } \\
\text { ATUAÇÃ } \\
0\end{array}$ & $\begin{array}{l}\text { POPULAÇÃO } \\
\text { ANALFABETA } \\
\text { MAIOR DE } 15 \\
\text { ANOS }\end{array}$ & $\begin{array}{l}\text { META DE } \\
\text { EDUCAN } \\
\text { DOS }\end{array}$ & $\begin{array}{l}\text { N. }{ }^{\circ} \quad \text { DE } \\
\text { EDUCAN } \\
\text { DOS } \\
\text { INSCRIT } \\
\text { OS }\end{array}$ & $\begin{array}{l}\text { N. }{ }^{\circ} \quad \text { DE } \\
\text { EDUCAN } \\
\text { DOS } \\
\text { FREQUEN } \\
\text { TES }\end{array}$ & $\begin{array}{l}\text { N. } .^{\circ} \quad \text { DE } \\
\text { EDUCAN } \\
\text { DOS } \\
\text { ALFABETI } \\
\text { ZADOS }\end{array}$ & $\begin{array}{l}\text { IMPACTO } \\
\text { NO N. } .^{\circ} \text { DE } \\
\text { ANALFABE } \\
\text { TOS }\end{array}$ \\
\hline $\begin{array}{l}\text { Água } \\
\text { Doce do } \\
\text { Maranhão }\end{array}$ & 2.836 & 1.520 & 853 & 665 & 499 & $17.6 \%$ \\
\hline $\begin{array}{l}\text { Aldeias } \\
\text { Altas }\end{array}$ & 5.771 & 2.820 & 3.010 & 2.930 & 2.197 & $38 \%$ \\
\hline $\begin{array}{l}\text { Governad } \\
\text { or } \\
\text { Newton } \\
\text { Bello }\end{array}$ & 2.771 & 1.520 & 948 & 873 & 655 & $23,64 \%$ \\
\hline $\begin{array}{l}\text { Itaipava } \\
\text { do Grajau }\end{array}$ & 3.071 & 2.000 & 1.485 & 1.319 & 989 & $32,2 \%$ \\
\hline $\begin{array}{l}\text { Jenipapo } \\
\text { dos } \\
\text { Vieiras }\end{array}$ & 3.291 & 1.800 & 852 & 720 & 540 & $16,4 \%$ \\
\hline $\begin{array}{l}\text { Santana } \\
\text { do } \\
\text { Maranhão }\end{array}$ & 2.629 & 2.000 & 1.508 & 1.336 & 1.002 & $38,11 \%$ \\
\hline $\begin{array}{l}\text { São João } \\
\text { do Caru }\end{array}$ & 2.635 & 1.000 & 1.200 & 1.140 & 855 & $32,44 \%$ \\
\hline $\begin{array}{l}\text { São } \\
\text { Raimund } \\
\text { o do Doca } \\
\text { Bezerra }\end{array}$ & 1.523 & 800 & 610 & 509 & 382 & $25 \%$ \\
\hline TOTAL & 24.340 & 14.040 & 10.466 & 9.492 & 7.119 & $27.92 \%$ \\
\hline
\end{tabular}

Fonte: MST (2017). Balanço elaborado pela Coordenação Político Pedagógica da Jornada. Fevereiro de 2017.

A meta inicial para a primeira fase era de 14.040 , no entanto, a Jornada conseguiu mobilizar um número de educandos menor do que o previsto, já que tiveram 10.466 inscritos para as turmas. Inúmeros fatores foram apontados como motivos para que a meta não fosse atingida, como citado por Guedes, Pinheiro e Batista:

Entre os fatores que colaboraram para este resultado encontra-se o pouco tempo e reduzida equipe para a mobilização, a resistência de muitos potenciais educandos a voltarem aos estudos, o período de chuvas em que esta ação foi realizada, que dificultou muito o acesso a povoados distantes e o fato de existirem outros programas, como o Brasil Alfabetizado, implantados nos municípios, 
que embora não estivessem em funcionamento naquele momento absorviam parte de nosso público-alvo. Outro fator que vale ser destacado como entrave à abertura de turmas foi o número de educandos necessário para sua abertura (20 educandos), número muito alto se considerarmos o tamanho de diversas comunidades rurais. (GUEDES; PINHEIRO; BATISTA, 2019, p. 138).

Embora a meta inicial não tenha sido atingida, dos 9.492 educandos frequentes 7.119 foram alfabetizados, representando $75 \%$ dos educandos, um percentual bastante alto, que impactou, significativamente, a realidade do analfabetismo dos municípios, como em Santana do Maranhão, que em um ano reduziu em 38,11\% o número de analfabetos. Estes resultados foram motivadores que incentivaram a continuação do programa. Com a boa receptividade nos municípios da primeira fase, o governo do estado, juntamente ao Movimento, projetou uma segunda fase com intuído de atingir não só 8 (oito) mas 15 (quinze) municípios do Plano do Mais IDH, levando educação para os municípios que já estavam desacreditados por outros programas de alfabetização de jovens e adultos.

A segunda fase da Jornada aconteceu em 15 municípios do estado: Afonso Cunha, Água Doce do Maranhão, Aldeias Altas, Belágua, Governador Newton Bello, Itaipava do Grajaú, Jenipapo dos Vieiras, Lagoa Grande do Maranhão, Marajá do Sena, Milagres do Maranhão, Santa Filomena do Maranhão, Santana do Maranhão, São João do Caru, São Raimundo do Doca Bezerra, São Roberto que faziam parte do Plano Mais IDH.

Dada a amplitude da segunda fase da Jornada, a Brigada de Alfabetização Salete Moreno foi ampliada para 37 membros: 28 brigadistas que atuaram nos municípios e 8 que atuaram na coordenação política e pedagógica CPP. Dessa vez, os brigadistas vieram de 11 estados do Brasil: Bahia, Ceará, Maranhão, Minas Gerais, Pará, Paraíba, Paraná, Piauí, Rio Grande do Sul, Rondônia e Tocantins. A atuação se estendeu para os seguintes municípios, abaixo descrevemos a realidade do analfabetismo nos sete municípios incorporados na segunda fase. 
Para seguir revertendo o severo quadro do analfabetismo nos municípios de menor IDHM, estabelece-se a seguinte meta e obtêmse os seguintes resultados, conforme Tabela 02.

Tabela 2 - Metas e quantitativo de sujeitos alfabetizados pela $2^{\text {a }}$ fase da Jornada de Alfabetização do Maranhão

\begin{tabular}{|c|c|c|c|c|c|c|c|c|}
\hline $\begin{array}{l}\text { N. } \\
0\end{array}$ & $\begin{array}{l}\text { MUNICIPIO } \\
\text { S }\end{array}$ & $\begin{array}{l}\text { POPULAÇ } \\
\text { ÃO } \\
\text { ACIMA DE } \\
15 \text { ANOS } \\
\text { NÃO } \\
\text { ALFABETI } \\
\text { ZADA }\end{array}$ & $\%$ & $\begin{array}{l}\text { META } \\
2^{a} \\
\text { FASE }\end{array}$ & $\begin{array}{l}\text { MATRIC } \\
\text { ULADOS } \\
2^{\mathrm{a}} \text { FASE }\end{array}$ & $\begin{array}{l}\text { EDUCA } \\
\text { NDOS } \\
\text { FREQU } \\
\text { ENTES } \\
2^{\text {a }} \text { FASE }\end{array}$ & $\begin{array}{l}\text { ALFABE } \\
\text { TIZADO } \\
\text { S } \mathbf{2}^{\mathrm{a}} \\
\text { FASE }\end{array}$ & $\begin{array}{l}\text { TAXA DE } \\
\text { ANALFABE } \\
\text { TISMO } \\
\text { PÓS } \\
\text { FASE }\end{array}$ \\
\hline 1 & \begin{tabular}{|l} 
Afonso \\
Cunha
\end{tabular} & 1.277 & 34,6 & 639 & 646 & 435 & 498 & $21,1 \%$ \\
\hline 2 & $\begin{array}{|lr|}\text { Água } & \text { Doce } \\
\text { do Maranhão }\end{array}$ & 2.337 & 29,6 & 2.277 & 2.410 & 1.392 & 1.473 & $10,9 \%$ \\
\hline 3 & $\begin{array}{l}\text { Aldeias } \\
\text { Altas }\end{array}$ & 3.574 & 23,3 & 2.852 & 3.297 & 2.405 & 2.579 & $6,49 \%$ \\
\hline 4 & Belágua & 1.442 & 39,2 & 721 & 724 & 498 & 529 & $24,8 \%$ \\
\hline 5 & $\begin{array}{l}\text { Governador } \\
\text { Newton } \\
\text { Bello } \\
\end{array}$ & 2.116 & 27,6 & 1.974 & 754 & 459 & 552 & $20,4 \%$ \\
\hline 6 & \begin{tabular}{|l|} 
Itaipava \\
Grajaú
\end{tabular} & 2.082 & 23,1 & 2.156 & 2.163 & 1.889 & 1.900 & $2 \%$ \\
\hline 7 & \begin{tabular}{|l|} 
Jenipapo dos \\
Vieiras
\end{tabular} & 2.751 & 28.5 & 2.380 & 2.703 & 2.016 & 1.547 & $12,5 \%$ \\
\hline 8 & $\begin{array}{l}\text { Lagoa } \\
\text { Grande do } \\
\text { Maranhão }\end{array}$ & 2.333 & 35,3 & 700 & 1.012 & 783 & 796 & $23,2 \%$ \\
\hline 9 & $\begin{array}{l}\text { Marajá do } \\
\text { Sena }\end{array}$ & 1.944 & 40 & 584 & 994 & 561 & 620 & $27,2 \%$ \\
\hline 10 & $\begin{array}{l}\text { Milagres do } \\
\text { Maranhão }\end{array}$ & 1.795 & 35,4 & 718 & 754 & 495 & 433 & $26,8 \%$ \\
\hline 11 & $\begin{array}{l}\text { Santa } \\
\text { Filomena }\end{array}$ & 1.464 & 31,6 & 732 & 1.092 & 937 & 870 & $12,82 \%$ \\
\hline 12 & \begin{tabular}{|l|} 
Santana do \\
Maranhão
\end{tabular} & 1.627 & 21,2 & 1.158 & 1.211 & 806 & 677 & $12,4 \%$ \\
\hline 13 & $\begin{array}{l}\text { São João do } \\
\text { Caru }\end{array}$ & 1.784 & 23,4 & 1.495 & 950 & 515 & 456 & $17,4 \%$ \\
\hline 14 & \begin{tabular}{|l|} 
São \\
Raimundo \\
do Doca \\
Bezerra
\end{tabular} & 1.141 & 28,4 & 997 & 674 & 460 & 488 & $16,2 \%$ \\
\hline 15 & São Roberto & 1.384 & 34,7 & 692 & 650 & 394 & 445 & $23,5 \%$ \\
\hline \multicolumn{2}{|c|}{ TOTAL } & 30.051 & 30,1 & 20.075 & 20.034 & 14.045 & 13.863 & $17,2 \%$ \\
\hline
\end{tabular}

Fonte: MST (2017). Balanço elaborado pela Coordenação Político Pedagógica da Jornada. Fevereiro de 2017. 
A meta inicial a ser atingida nesses 15 municípios era de 20.075 educandos, que foi praticamente atingida, já que foram inscritos no programa 20.034 jovens, adultos e idosos. No entanto, desse montante, apenas 14.045 educandos permaneceram na Jornada, representando uma evasão de $30 \%$. Entre os principais fatores de evasão, o Relatório Final da Brigada de Alfabetização aponta para o atraso nas ações oftalmológicas:

A Brigada aponta que grande parte desta evasão poderia ter sido evitada caso as ações oftalmológicas e a entrega dos óculos tivesse sido realizada logo no início da Jornada, pois grande parte das evasões foram relacionadas a problemas de visão, tendo sida relatada a evasão por outros problemas de saúde ou por migração como outros dois fatores recorrentes, embora menos relevantes. Somente a título de ilustração descreve. (MST, 2018, p. 23).

Ainda segundo esse relatório ${ }^{4}$, outros fatores contribuíram para a evasão dos educandos, como: o período de colheita ${ }^{5}$, o período de fortes chuvas, a intensa migração em busca de melhoria de vida ou trabalho em outros estados, a precária condição das estradas e o atraso no pagamento de bolsa de educadores e coordenadores, que levaram à desmotivação e até à paralisação das aulas. Esses fatores contribuíram diretamente, segundo os relatórios, para que o número de educando diminuísse. Embora o número de evadidos seja significativo e que deva ser trabalhado, aqueles que permanecem nas aulas até o final obtiveram excelentes resultados, já que dos 14.045 educandos frequentes, 13.863 foram alfabetizados. Vale, ainda, ressaltar que a Jornada conseguiu mobilizar, em dois anos de atuação, muitas pessoas diretamente e indiretamente, totalizando cerca de 30.500 educandos, tendo alfabetizado 20.982 jovens, adultos e idosos.

\footnotetext{
${ }^{4}$ A Brigada Salete Moreno produzia mensalmente relatórios de cada município, do qual se extraia um relatório geral e que serviram de base para o Relatório Final da Jornada. Esses relatórios foram cedidos a mim, desde já agradeço ao MST pela colaboração.

${ }^{5}$ As colheitas acontecem em outros estados, como migração temporária, que às vezes se tornam permanente, o que causa um intenso processo migratório.
} 
Os números não mostram todos os frutos da Jornada. $\mathrm{O}$ quanto ela foi importante para reaproximar pessoas que não se falavam há anos, devido à vida dura dos trabalhadores do campo e da cidade, promovendo o reencontro das donas de casas que moravam distantes das "cumades". Foram tantos casos que não é possível mensurar, em números, o quanto é significativo aprender a manusear um lápis ou até mesmo uma "lapiseira", poder ler seu o nome e de seus filhos no registro e não se envergonhar com a pergunta: o senhor é analfabeto? Não precisar usar a almofada para pôr o dedo, de ter nos seus documentos o seu nome escrito por si mesmo, de sabe ler o nome dos lugares, de não perder o ônibus ou até mesmo saber o número da poltrona que iriam sentar, de escrever o nome para bater o ponto do trabalho e saber contar as horas que trabalhou para não ser mais enganado. Seria frio demais, apenas, analisar os números, mesmo que sejam muito significativos, pois a Jornada iria muito além de metas numéricas, já que elas não preveem ver as lágrimas caindo quando se aprende a usar um lápis sem rasgar o papel, pois as mãos não estavam acostumadas com o peso do lápis, mas sim ao trabalho árduo de toda uma vida. A mesma emoção que presenciávamos nos jovens de 15 anos, que já tinham trabalhado muito mais que muita gente, gente que usurpou o direito dessas pessoas à educação. Continuaremos afirmando que a Jornada de Alfabetização do Maranhão - Sim, eu posso! e Círculos de Cultura teve a tarefa de mudar não apenas os indicadores municipais da educação, mas também a vida desses maranhenses que fizeram parte da Jornada.

\section{A AVENTURA PEDAGÓGICA DA JORNADA DE ALFABETIZAÇÃO}

\section{Sim, eu posso! Alfabetizar, alfabetizar!}

Como já afirmamos, o método cubano, Sim, eu posso! Já havia sido executado no Maranhão no governo de Jackson Lago. Uma primeira experiência que contribuiu para iniciarmos o caminho de superarmos o analfabetismo no estado. O método já possibilitou a 
alfabetização de mais de 8 milhões de pessoas em mais de 15 países, de acordo com os parâmetros da Organização das Nações Unidas para a Educação, a Ciência e a Cultura (UNESCO). No Brasil, o guardião do método é o MST, que, desde 2006, desenvolve o trabalho de alfabetização em suas áreas de assentamentos e acampamentos, utilizando o Sim, eu posso!

O método se apresenta como novo devido ser caracterizado por uma ação alfabetizadora de abordagem analítico-sintética, ou seja, o processo de alfabetização parte sempre de uma contextualização, do estudo de uma frase que contém a palavra integradora, que servirá de base para a aprendizagem. A proposta metodológica consiste em aulas presenciais, que são mediadas por um educador diariamente, com base em recursos audiovisuais, recebendo o apoio pedagógico de um coordenador, que colabora no processo de ensino-aprendizagem.

A metodologia utiliza no processo alguns instrumentos que auxiliam como suporte pedagógicos: instrumento tecnológico (videoaulas) e acessórios visuais (cartilha do alfabetizando). As videoaulas têm o formato de uma "novela", que se passa em uma sala de aula de alfabetização de jovens e adultos, onde os educandos vão se alfabetizando com o passar do tempo, sempre retratando situações semelhantes às vivenciadas pelos educandos na condição de sujeito não alfabetizado.

A partir do estudo de uma frase que contém a palavra integradora, que servirá de base para a aprendizagem, as letras do alfabeto são associadas a números, partindo do pressuposto que os jovens e adultos têm mais familiaridade com os números embora não consigam escrever sua representação gráfica. Essa associação permite que aos poucos decodifiquem as letras, formando novas palavras e novas frases.

A experiência da Jornada demonstra que a utilização dos recursos audiovisuais e de atividades lúdicas são facilitadores da aprendizagem e, por esse motivo, a pedido da Brigada, Marquinhos Monteiro, músico popular do MST, compôs músicas para as aulas, que se referiam ao Sim, eu posso!, e que eram cantadas em todas as salas de aulas, como a que segue abaixo, que se refere à 
correspondência entre os números e as vogais, e ainda aborda valores disseminados pela Jornada.

Para escrever não basta só usar o olho

Usar o fura bolo, com o apoio do mata piolho.

Vamos agora estudar

$\mathrm{O}$ "um" representa o "A"

Pega no lápis seu José

$\mathrm{O}$ "dois" representa o " $\mathrm{E}$ "

Sei que eu posso sim

O "três" representa o "I"

Ser solidário é bem melhor

$\mathrm{O}$ "quatro" representa o "O"

Lutar para o bem comum

$\mathrm{O}$ "cinco" representa o "U"

Ter uma telenovela nas salas de aulas, com personagem que tinham a história de vida parecida com a dos educandos, fazia a diferença, muitos tinham seus personagens favorito, se afeiçoavam por Ângela, a professora da telenovela, por Aparecido, o apresentador e por outros tantos personagens, muitos protagonizados por militantes do MST, que não eram atores, tendo sido alguns deles alfabetizados durante o processo das gravações, que aconteceu em Cuba, em 2005.

Muitos educandos comentavam durante o caminho de volta para casa sobre a palavra integradora, as salas de aulas, nos quintais, nas casas de farinhas, nas casinhas de taipas que juntavam os educandos, pais, mães, vizinhos, avós, que por vezes foram alfabetizadas pelos netos, e muitas crianças que rondavam as aulas com seus olhares curiosos.

As turmas que aconteciam nas escolas, juntamente a outras turmas como o Ensino Médio, tinham fatos interessantes, como nos casos em que idosos, na hora do intervalo, montavam as frases com os números e desafiavam os alunos do Ensino Médio a lerem. Estes não conseguiam e, posteriormente, os idosos montavam as frases em 
letras, revelando o enigma e ainda diziam: "viu como eu não sou mais analfabeto?".

Era bonito de ver a sala criando vida, com os exercícios expostos nas paredes, com ornamentações aconchegantes, que faziam com que os espaços não fossem apenas a casa de farinha, mas a casa de farinha da sala do Sim, eu posso!. Os ambientes alfabetizadores contavam muito para a aprendizagem dos sujeitos, fazia com que eles se sentissem construtores permanentes daqueles espaços, Ihes dava pertença.

No início da Jornada, foram disponibilizados pelo Governo do Estado os kits para cada educando: camisa, lápis apropriado para alfabetização de jovens e adultos, caderno e uma mochila. Era gostoso de ver a reação das pessoas recebendo os kits, tudo era motivo de comemoração.

O método teve duração de 4 meses, mas houve alguns atrasos que seriam determinantes para alfabetização dos sujeitos, com as consultas oftalmológicas, que seriam disponibilizadas pelo Governo do Estado. $O$ atraso nas consultas prejudicou os educandos. Muitos tinham problemas de baixa visão e não tinham condições financeiras para fazer as consultas por conta própria. Era uma situação difícil de presenciar, ver os olhos lacrimejando no esforço de enxergar as letras. Os educadores e educadoras eram muito bons e construíam estratégias para auxiliar estes educandos, escreviam em letras grandes para que todos pudessem ver, faziam atendimento individual, mesmo assim muitos não conseguiram prosseguir nas aulas e tiveram de abandoná-las.

A Brigada tinha a tarefa diária de saber dos óculos e das consultas oftalmológicas em conversa com o Governo do Estado, conversas que sempre prometiam uma nova data, sempre adiada. Nas visitas de turmas, observamos que após o "boa noite", surgia a pergunta: "cadê os óculos?". O fato era que não eram somente os óculos iam demorar, o que os educandos sentiam a perda da oportunidade de enxergar as letras e números para poder se alfabetizar, com isso houve inúmeras desistências, que não foram por falta de tentativas, foram embora porque a dor era maior.

Os que conseguiram chegar até o final dos quatro meses de método Sim, eu posso!, e escreveram seu nome e pequenas frases, 
tiveram a felicidade de ver um sonho se tornando realidade. Não havia provas mensais para medir o conhecimento, mas havia a carta final proposta pelo método, que cada educando tinha que escrever para alguém. Muitos escreveram para os filhos distantes, outros para as esposas e muitos para os amigos, ou mesmo educadores. Era tanta felicidade expressa naquelas cartas, pois elas representavam um diploma pela conquista da escrita e da leitura, sabiam que ali era apenas um primeiro passo, sabendo também que o Sim eu posso! Era, apenas, alfabetização e não uma faculdade, mas talvez fosse uma faculdade de experiências de vidas.

Mas a tarefa era a continuidade, o aperfeiçoamento da leitura e da escrita e de uma leitura do mundo. Muitas turmas cresceram e outras diminuíram ao decorrer do processo, muitos fatores já ditos contribuíram para isso, fato é que os Círculos de Cultura já estavam prestes a iniciar e as mobilizações e formações já haviam iniciado.

\section{Círculos de Cultura}

Os Círculos de Cultura se apresentam como uma forma transformadora de pensar e organizar processos educativos, pois vão além de uma sala de aula, na medida em que se contrapõe à pedagogia tradicional, em que a organização do ensino é centrada nos educadores, para valorizar processos em que educandos e educadores dialogam, mediados por sua experiência de mundo. Nos Círculos de Cultura, o educador ou a educadora mediará e motivará as discussões e produções, possibilitando que todos ensinem e aprendam com base em temas da realidade local. Entendendo, a alfabetização "como a ação capaz de levar o analfabeto a pensar reflexivamente seu pensamento, desenvolver a consciência crítica, introduzi-lo num processo real de democratização da cultura e de libertação" (FREIRE, 2000, p. 25).

Nos Círculos as vivências construídas eram de suma importância, pois as aulas se tornavam grandes comemorações e rodas de debates. Poderíamos dizer que os educadores que participaram dos Círculos fizeram o que propõe Paulo Freire; se tornaram animadores de debates, com motivação diária, de forma interativa para trabalharem a palavra geradora, problematizando a 
vida do educando e de sua comunidade, para compreender à realidade como um todo. Esta era uma tarefa de uma magnitude enorme.

O Círculo de Cultura não é uma técnica, não pode ser compreendido como um grupo para desenvolver tarefas ou uma roda de conversa sem consequências na vida das pessoas. Temos que cuidar para que o termo não entre em defasagem e confusão generalizada que $\mathrm{o}$ desqualifique, desviando-o de sua construção real, que é implementar ações culturais em diálogo com os sujeitos, na disposição de envolvimento nas lutas por direitos. Ação cultural para a liberdade, como nos ensinou Paulo Freire. (CÉSAR; ARAÚJO, 2019, p. 108).

Neles os educandos se sentem parte do processo, fazendo com que as turmas sejam um espaço de aprendizagem coletiva e não hierarquizada, com uma educação horizontal. A forma como os sujeitos são vistos faz com que cresçam e se posicionem, com a sua própria leitura de mundo, a partir da sua realidade.

O educador tem de conhecer a realidade da localidade e da vida dos seus educandos, suas histórias de vida e da comunidade. Tem de estudar e planejar qual tema se encaixa na realidade dos educandos, tendo como referência os eixos que foram definidos previamente por um estudo feito pela Brigada Salete Moreno, a partir das realidades locais de cada comunidade. A partir desse estudo, no quadro 01 , definem-se os eixos de trabalho.

Quadro 1 - Eixos temáticos norteadores do trabalho com os círculos de cultura

\begin{tabular}{|l|l|}
\hline História, Cultura e Identidade & \multicolumn{1}{c|}{ Trabalho } \\
\hline História e vida & Direitos trabalhistas \\
História e memória local & Emprego e geração de renda \\
Etnia & Trabalho como princípio educativo \\
Classe social & Produção cultural e artística com trabalho \\
Práticas culturais & \\
Família & \\
\hline
\end{tabular}




\begin{tabular}{|l|l|}
\hline \multicolumn{1}{|c|}{ Terra e Território } & \multicolumn{1}{c|}{ Direito e Democracia } \\
\hline $\begin{array}{l}\text { Meio ambiente } \\
\text { Concentração fundiária }\end{array}$ & Educação (EJA - continuidade; práticas \\
Desmatamento & educativas informais) \\
Seca & Cidadania \\
Saúde & Participação \\
Alimentação saudável e & Transporte \\
produção & Meios de comunicação \\
\hline
\end{tabular}

Fonte: Caderno do Educador - Círculos de Cultura (2018, p. 5). Elaboração Brigada Nacional de Alfabetização Salete Moreno.

A partir desses Eixos Temáticos, cada coletivo de educadores construía um processo de seleção de temas, definidos coletivamente nos Plantões Pedagógicos, tendo como base as histórias de vida e comunitárias da localidade em que atuavam. Os temas, escolhidos como desdobramento dos Eixos Temáticos, tornavam-se problematizações sobre a vida dos educandos e educadores de cada município, de sua realidade local, desvelando processos sociais naturalizados durante anos, não perdendo de vista o objetivo de aperfeiçoamento da leitura e da escrita.

O exercício da leitura e da escrita no Círculo de Cultura se alicerça no debate das questões centrais presentes nas formas de produção e reprodução da existência, nas ações do cotidiano como: trabalho, coletividade, alimentação, saúde, formas de organização comunitária, política, economia, direitos sociais, religiosidade, cultura, entre outros. Questões estas que estão relacionadas à prática social, buscando intervir e alterar as atuais relações no mundo do trabalho e na vida dos educandos, com a compreensão de que o processo de ensinoaprendizagem deve considerar os sujeitos em todas as suas dimensões. (MST; SEDUC, 2016, p. 16).

Ao contrário de outros métodos de ensino utilizados na alfabetização de jovens e adultos, no qual a metodologia de ensino que era pensada e utilizada de fora para dentro, os métodos de ensinos proposto pela Jornada são o oposto dessas experiências, 
pois os dois métodos utilizados têm como princípio a realidade dos jovens e adultos.

A Jornada, de forma geral, mobilizava muita gente, mas os Círculos tinham como finalidade última estender seus processos para além das salas de aula e conseguiam, com feiras culturais, cinema da terra, gincanas e muitas outras atividades que partiam da iniciativa de educandos e educadores, da própria comunidade, mas também da Brigada.

\section{CONSIDERAÇÕES FINAIS}

Recuperar a experiência da Jornada de Alfabetização do Maranhão, não faria sentido se não pudéssemos nos distanciar, minimamente, desse processo para podermos apontar os limites e possibilidades que despontam dessa experiência. Pensamos que somente assim poderemos contribuir para apontar os desafios inerentes a uma próxima fase, ou tirarmos lições para que essa experiência, ao ser replicada em outros lugares, dê os saltos qualitativos necessários e reforce determinadas práticas que avaliamos como pilares fundamentais da práxis pedagógica desenvolvida pela Jornada.

Um dos principais limites, encontrados para o desenvolvimento do trabalho, refere-se aos atrasos. Este foi um dos maiores condicionantes do processo, pois houve atrasos em relação ao início das aulas, ações oftalmológicas, entrega de materiais, liberação de recurso para a realização de atividades, que acarretaram, também, atrasos de pagamentos de bolsas de educadores e coordenadores de turma, que ficaram sem receber por três meses.

Os primeiros atrasos ocorreram logo no início da Jornada, com a falta de recursos e materiais para a realização das formações iniciais de educadores e coordenadores. A avaliação da Coordenação Pedagógica da Jornada era de que deveríamos seguir com o cronograma de atividades, fazendo a formação com o apoio de aliados, o que aconteceu, embora prejudicasse, em alguma medida, sua qualidade, por falta de infraestrutura adequada.

$\mathrm{O}$ atraso relativo ao pagamento das bolsas de educadores e coordenadores de turmas também foi fator limitante do processo, 
pois causou insegurança e tensões desnecessárias no coletivo. Muitos dos profissionais tinham na bolsa sua única fonte de renda, ou esta compunha o orçamento familiar de forma significativa e os atrasos interferiam na sobrevivência de famílias inteiras. Ainda no caso dos coordenadores, o atraso, também, se estendia às diárias que recebiam para o acompanhamento das turmas, recurso que era usado para deslocamento para as visitas, mas que também supria necessidades dos Núcleos de Turmas, principalmente nas atividades comunitárias. Apesar de termos um coletivo muito comprometido, que não deixava que essa tensão transparecesse no ambiente educativo, a desmotivação era visível nos rostos, quando nos reuníamos.

Contudo, o atraso que teve maior impacto para o desenvolvimento da Jornada foi o das ações oftalmológicas. Em nosso cronograma, os educandos que precisavam de óculos deveriam estar de posse deles até, no máximo, o primeiro mês de aulas, mas somente tiveram acesso a eles no último mês, após quase 7 meses. As triagens oftalmológicas, realizadas no período previsto, em parceria com a Força Estadual de Saúde, indicaram alto percentual de educandos com baixa visão, o que era perceptível durante as aulas. Mas as consultas e, posteriormente, a entrega dos óculos se arrastou por meses a fio, dificultando a aprendizagem dos educandos.

A presença dos educandos em sala de aula estava sendo dificultosa em virtude da falta de óculos. Em ambiente noturno, torna-se ainda maior a dificuldade em conseguir enxergar as letras e números. Os educadores buscavam desenvolver estratégias para sanar o problema, como o uso de lanterna pequena para que pudessem ver melhor as letras, a criação de um ambiente motivacional e lúdico, mas, mesmo assim, esse fator causou um processo de evasão massiva. Isso se agravou no período da chuva, com a frequente falta de luz na maioria das comunidades e povoados, impedindo o uso dos equipamentos, e com as ruas enlameadas, que dificultavam a chegada dos idosos às aulas. Esses fatores limitantes poderiam, na grande maioria das vezes, ter sido evitados com ajustes administrativos e de articulação entre as secretarias governamentais responsáveis pela gestão do programa. 
Outro limite encontrado pela Jornada foi fazer com que o povo acreditasse nesta. Logo, vimos que teríamos de enfrentar dois desafios: (1) convencer o povo de que era possível se alfabetizar e, ao mesmo tempo, (2)convencê-lo de que, dessa vez, tratava-se de uma política séria, comprometida com a alfabetização da população. A população estava convencida que a Jornada iria ser como outros programas de alfabetização que passaram pelo município, programas fantasmas, que inscreviam educandos em aulas que jamais aconteciam, mas que apareciam nas estatísticas como realizadas, causado tamanha descrença em programas desta natureza.

Muitas outras dificuldades foram enfrentadas, como falta de infraestrutura local para aulas, povoados de difícil acesso, dificuldades para a mobilização e manutenção dos educandos em sala, mas todos esses fatores eram esperados pela Brigada de Alfabetização, que criou inúmeras estratégias para seu enfrentamento, resultando em belos frutos produzidos pela Jornada. O processo da Jornada de Alfabetização do Maranhão apontou um conjunto de potencialidades dessa experiência. Optamos por ressaltar algumas: a formação de educadores e coordenadores de turmas, a formação dos educandos e os vínculos entre a educação popular e movimento social na condução do programa.

Os educadores e coordenadores também foram transformados por esse processo. Logo nas primeiras formações sobre o método Sim, eu posso!, muitos educadores, e até mesmo coordenadores, tiveram resistência às metodologias propostas. Acharam que não iria dar certo, duvidado até que este poderia levar a resultados positivos. Porém, ao longo do processo, com a formação, os Plantões Pedagógicos, reuniões e a prática em sala de aula, perceberam que os educandos aprendiam com maior facilidade, associando letras e números, a partir da palavra integradora. Esse processo fez com muitos educadores revissem sua prática pedagógica e outros se descobrissem como educadores, agora inundados pela educação popular e por um amor incondicional ao povo e ao compromisso de alfabetizá-lo.

Pudemos perceber que as pessoas que participaram da Jornada de Alfabetização, direta e indiretamente, se transformaram, passaram a viver diariamente na coletividade, não somente nos 
horários das aulas, mas também aos finais de semana. Um encantamento com a redescoberta da sua própria comunidade, uma reconciliação com sua história. Percebemos que as atividades desenvolvidas durante a Jornada de Alfabetização tratava-se de um processo de formação humana em suas diversas dimensões.

Dentre elas, a educação popular foi sentida e vivenciada por esse povo, em cada mutirão estavam os educadores, dedicados a educar, sentir a lágrima correr quando um aluno aprendia escrever e ler o nome, sentido na pele a conquista da escrita do educando, que foi uma conquista de todos da turma.

O avanço foi na sensibilidade, nos sorrisos, nos abraços sinceros, nas histórias de vida sendo expostas e sentidas pela turma. Compromisso sentido quando ocorreram os atrasos de bolsas, mas que fazia falta a esses educadores, mas que, mesmo passando dificuldades, não desistiram, mesmo quando faltava a gasolina para os coordenadores chegarem às turmas, e muitas outras coisas, como o giz ou o recurso para fazer um bolo para o lanche.

Pensamos que o fato de a coordenação do programa ser feita por um movimento popular contribuiu para todo esse engajamento. Todos sabiam que a brigada que ali estava não era representante do governo, que se ali estava, se dedicando dia após dia à Jornada, o fazia por compromisso com o povo, porque acreditava que, por meio da alfabetização, poderia mudar a realidade local e do país. Essa convicção inspirava educadores e coordenadores, que seguiam firmes em sua tarefa.

Destarte, a Jornada, ainda, tem grande desafios pela frente, um deles é fazer com que os sujeitos continuem se organizado em busca de seus direitos. Para isso, seria preciso criar instrumentos de organização popular para que, mesmo após o término da Jornada, o povo continue organizado, fazendo com que essa sociabilidade não se perca. Que instrumentos dariam conta de fazer com que o povo se mantenha organizado na luta por direitos? Que permaneça mobilizado no desejo de estudar, lutando por acesso e condições que garantam sua permanência na escola, consciente de seus direitos? Estas são perguntas que ainda precisam ser respondidas pelas próximas fases do programa. 
Pois, sabemos que o processo de tomada de consciência não é linear, ele avança e recua, conforme a conjuntura e a forma com que ela é vivenciada pelos sujeitos. A alfabetização é um dos primeiros passos para a tomada de consciência. É necessário que ela seja alimentada pela coletividade, entendendo que a educação é transformadora, os vínculos conquistados pelas comunidades, por meio da Jornada, precisam permanecer ativos, como motor mobilizador de outros processos de escolarização e luta.

Por fim, buscamos juntos aos gestores municipais do Maranhão, estratégias para que os educandos sigam estudando, para que a educação chegue a todos os povoados e comunidades, uma educação que possa possibilitar a vivência de processos emancipatórios. Talvez esse seja um dos grandes desafios a que nos propomos. Oxalá, que possamos cumpri-lo!

\section{REFERÊNCIAS}

BRASIL. Constituição da República Federativa do Brasil de 1988. Brasília: Senado Federal, Centro Gráfico, 1988.

CÉSAR, M. R.; ARAÚJO, J. I. Um encontro na história de emancipação: Sim, eu posso! e Círculos de Cultura. In: Jornada de Alfabetização do Maranhão: mobilização popular, cultura e emancipação. São Luís: EDUEMA, 2019.

FREIRE, P. A importância do ato de ler: em três artigos que se completam. 42. ed. São Paulo: Cortez, 2000.

FREIRE, P. Cartas a Cristina. São Paulo: Editora Unesp, 2002.

GUEDES, L.; PINHEIRO, I.; BATISTA, R. Do que podem nos dizer os números da primeira fase da Jornada de Alfabetização do Maranhão. In: Jornada de Alfabetização do Maranhão: mobilização popular, cultura e emancipação. São Luís: EDUEMA, 2019.

IBGE, Instituto Brasileiro de Geografia e Estadística. Censo Demográfico. 2010. IBGE, 2010. Disponível em: https://censo2010.ibge.gov.br/. Acesso em: 04 fev. 2018. 
IMESC, Instituto Maranhense de Estudos Socioeconômicos e Cartográficos. Plano de ação mais IDH: diagnóstico preliminar / Instituto Maranhense de Estudos Socioeconômicos e Cartográficos, Secretaria de Estado do Planejamento e Orçamento. São Luís, 2015.

MARANHÃO. Decreto $\mathbf{n}^{\circ}$. 30.612, de 02-01-2015. Institui o Plano de Ações Mais IDH e seu respectivo Comitê Gestor e dá outras providências. Governo do Estado do Maranhão, 2015. Disponível em: http://www.stc.ma.gov.br/legisla-documento/?id=3768. Acessado em: 04 fev. 2018.

MST; SEDUC. Caderno do Educador: Sim, eu posso! São Luís: SEDUC, 2016.

\section{MST; SEDUC. Relatório final da $\mathbf{2}^{\mathrm{a}}$ fase da Jornada de} Alfabetização do Maranhão - 2017/2018. São Luís, 2018. (mimeo). PERCASSI, J.; GUEDES, L. Alfabetização e emancipação humana: do pão à poesia. In: Jornada de Alfabetização do Maranhão: mobilização popular, cultura e emancipação. São Luís: EDUEMA, 2019.

Submetido em: Maio/ 2020.

Aceito em: Fevereiro/ 2021. 